\title{
"LET HER ALONE!" \\ KAJIAN PERANAN PEREMPUAN PADA YOHANES 12:1-8 MELALUI SISTEM NILAI HONOR AND SHAME
}

\author{
Hana \\ Sekolah Tinggi Teologi Amanat Agung \\ hanashi77@yahoo.com
}

\begin{abstract}
Abstrak
Isu gender dalam pelayanan gereja di zaman ini ternyata masih menjadi isu yang layak diperbincangkan. Kenyataan menunjukkan bahwa perempuan masih dibatasi peranannya untuk melayani di gereja maupun lembaga-lembaga Kristen yang ada. Padahal pelayanan bukan merupakan masalah gender, melainkan merupakan sebuah wujud kasih, penyembahan dan pengabdian kepada Tuhan, sekaligus merupakan sebuah panggilan dari Tuhan berdasarkan kemampuan dan talenta yang Tuhan berikan. Tidak seharusnya perempuan dilarang untuk melayani Tuhan di bidang apapun hanya karena gendernya. Perempuan seharusnya diberikan kesempatan yang sebesar-besarnya, seperti halnya laki-laki, untuk mewujudkan kasih, penyembahan dan pengabdiannya kepada Tuhan, berdasarkan panggilan dan kompetensi yang Tuhan berikan kepadanya. Pernyataan tesis ini akan dibuktikan dalam artikel ini melalui alasan-alasan yang menggunakan perspektif honor and shame dalam membaca teks Yohanes 12:1-8. Kisah Marta dan Maria dalam melayani Tuhan di Yohanes 12:1-8, yang apabila dibaca dari perspektif honor and shame, akan memperlihatkan respons Yesus yang menghargai dan memberikan posisi yang terhormat kepada perempuan, melalui pemberian makna terhadap pelayanan yang Maria lakukan. Dengan demikian, teguran "Let her alone!" dari Yesus kepada Yudas, menjadi teguran yang mengingatkan siapapun yang melarang perempuan melayani Tuhan hanya karena keberatan gender.
\end{abstract}

Kata kunci: honor and shame; pengurapan; peranan; perempuan; profetik

\begin{abstract}
The gender issue of serving in the churches today is still an issue worth discussing. The facts show that women are still limited in their role to serve in churches and Christian institutions. Serving is not a gender problem, but rather is an expression of love, worship, and devotion to God, as well as a calling from God based on the abilities and talents that God has given. Women should not be forbidden to serve God in any field just because of their gender. Women should be opened to as many opportunities as men, to manifest their love, worship, and devotion to God, based on the calling and competence that God has given. This thesis statement is proven in this article by giving reasons from the perspective of honor and shame in John 12: 1-8. The story of Martha and Mary in serving the Lord in John 12: 1-8, from the perspective of honor and shame, shows the response of Jesus who respects and gives an honored position to women, by giving meaning to the ministry that Mary did. Thus, the warning "Let her alone!" from Jesus to Judas, becomes a warning to anyone who forbids women from serving God merely due to objection to their gender.
\end{abstract}

Keywords: honor and shame; anointing; role; women; prophetic

\section{Pendahuluan}

Peranan perempuan dalam pelayanan gereja ternyata masih dibatasi oleh beberapa gereja hingga hari ini. Mereka yang membatasi peran perempuan dalam pelayanan gereja, khususnya pada posisi-posisi tertentu, menjadikan larangan Paulus (seperti dalam 
1Tim.2:11-12, 14 dan 1Kor. 14:34) sebagai normatif dalam gereja. Namun bagi mereka yang tidak menyetujui dibatasinya peranan perempuan dalam pelayanan, akan berpendapat bahwa larangan Paulus tersebut tidak terlalu relevan lagi bagi konteks masa kini dikarenakan budaya dan situasinya yang berbeda dengan masa kini. ${ }^{1}$

Pro dan kontra mengenai peranan perempuan yang seakan-akan diperlihatkan dalam surat-surat Paulus ini, maka beragam penelitian telah dilakukan. Namun penelitian terhadap surat-surat Paulus ini masih terasa kurang komprehensif jika belum meneliti tentang sikap Yesus sehubungan dengan isu peranan perempuan. Itulah sebabnya, selain penelitian terhadap surat-surat Paulus, maka penelitian terhadap kitab-kitab Injil perlu dilakukan guna mendapatkan pemahaman yang lebih komprehensif tentang peranan perempuan di dalamnya.

Injil Yohanes menjadi salah satu Injil yang layak untuk diselidiki agar dapat menemukan pemahaman Yesus tentang peranan perempuan dalam pelayanan. Yohanes memperlihatkan sensitivitas dan penghargaan yang mendalam terhadap perempuan, melalui pemilihan dan penggambarannya terhadap peristiwa-peristiwa yang terjadi dalam kehidupan Yesus. ${ }^{2}$ Yohanes dalam narasinya tentang perempuan, memperlihatkan dengan jelas sikap dan posisinya terhadap perempuan, jauh lebih jelas daripada Injil Lukas yang walaupun mengisahkan banyak narasi perempuan, tetapi seringkali masih dianggap ambigu. $^{3}$ Karen Thiessen dengan lugas mengatakan sikap Yesus yang dikisahkan oleh Yohanes, "The Johannine Jesus is not presented as seeking to modify the feminine role prevalent within Judaism; rather Jesus seems to ignore it altogether as he calls women to public ministry and affirms them in the face of male opposition". 4

Itulah sebabnya, penelitian terhadap peranan perempuan di Injil Yohanes perlu dilakukan. Sehubungan dengan batasan halaman yang ada, maka artikel ini hanya akan meneliti salah satu peranan perempuan dalam Injil Yohanes yakni peranan perempuan dalam Yohanes 12:1-8. Pengkajian ini akan menggunakan sistem nilai honor and shame sebagai perspektif dalam membaca teks yang ada, guna mendapatkan gambaran dan pemahaman yang lebih jelas tentang peranan perempuan melalui latar belakang sosial dan budaya yang ada pada saat itu.

${ }^{1}$ Mereka biasanya akan menggunakan ayat-ayat dari Galatia 3:28; Roma 16:1-3, 6, 12; Filipi 4:2-3 dan 1 Korintus 11:5, sebagai dasar argumentasinya (Karen Heidebrecht Thiessen, "Jesus and Women in the Gospel of John," Direction 19, no. 2 (1990): 52.

${ }^{2}$ Ibid., 53.

${ }^{3}$ Barbara E Reid OP, Choosing The Better Part?: Women in the Gospel of Luke (Collegeville: Michael Glazier, 1996), 3. Mengutip dari Jane Schaberg, “Luke,” The Women's Bible Commentary, ed. Carol A. Newsom and Sharon H. Ringe (Louisville: John Knox, 1992), 275-292.

${ }^{4}$ Thiessen, "Jesus and Women in the Gospel of John.", 53. 


\section{Konsep Honor and Shame pada Masyarakat Abad Pertama di Mediterania}

Bruce Malina, salah satu tokoh terkemuka dari pendekatan social scientific criticism, melakukan penelitian terhadap budaya antropologi Mediterania, dengan tujuan untuk memahami budaya dan sosial di balik naskah Perjanjian Baru. Malina mengidentifikasi persepsi-persepsi dan nilai-nilai penting dalam budaya Mediterania kuno, seperti konsep honor and shame, dan memperlihatkan bagaimana pola dari budaya ini diimplikasikan dan diekspresikan dalam tulisan biblika. ${ }^{5}$ Penelitian ini memperlihatkan bahwa kepedulian terhadap honor telah meresap ke dalam setiap aspek dari kehidupan masyarakat di dunia Mediterania, sehingga tidak mengherankan jika honor dianggap sebagai nilai yang fundamental, sebagai inti, hati, dan jiwa dalam kehidupan sosial. ${ }^{6}$

Honor adalah istilah umum yang merujuk pada kelayakan atau nilai positif seseorang, baik dalam pandangannya sendiri maupun dalam pandangan masyarakat. ${ }^{7}$ Honor berkaitan dengan evaluasi dan persepsi sosial. Honor dapat berfungsi sebagai daftar peringkat sosial yang memberikan hak kepada seseorang untuk berinteraksi secara khusus dengan orang yang sederajat dengannya, dengan atasannya atau bawahannya, sesuai dengan budaya yang ada dalam masyarakat. ${ }^{8}$ Honor merupakan reputasi publik yang akan menentukan pakaian yang seharusnya dikenakan oleh seseorang, menentukan gestur, pekerjaan, tempat duduk ketika makan bersama, lawan bicara, yang berhak berbicara, yang berhak memulai percakapan, dll. ${ }^{9}$

Honor dapat dimiliki secara pasif karena asal-muasal seseorang (yang disebut ascribed honor), misalnya karena kelahirannya, koneksi keluarga, atau dianugrahkan oleh orang yang terkemuka dan berkuasa. ${ }^{10}$ Selain itu, honor juga dapat diperoleh melalui usaha aktif (yang disebut acquired honor), misalnya dalam kontes sosial "challenge and riposte."11

\footnotetext{
${ }^{5}$ John H Elliott, What Is Social Scientific Criticism? (Minneapolis: Fortress, 1993), 24.

${ }^{6}$ Bruce Malina and Richard L. Rohrbaugh, Social Science Commentary on the Synoptic Gospels (Minneapolis: Fortress, 1993), 369.

${ }^{7}$ Jerome H. Neyrey, Honor and Shame in the Gospel of Matthew (Louisville: Westminster John Knox, 1998), 5.

${ }^{8}$ Bruce J. Malina and Jerome H. Neyrey, "Honor and Shame in Luke-Acts: Pivotal Values of the Mediterranean World," in The Social World of Luke-Acts: Models for Interpretation, ed. Jerome H. Neyrey (Peabody: Hendrickson, 1991), 26.

${ }^{9}$ Malina and Rohrbaugh, Social Science Commentary on the Synoptic Gospels, 370.

${ }^{10}$ Malina and Neyrey, "Honor and Shame in Luke-Acts: Pivotal Values of the Mediterranean World", 28.

${ }^{11}$ Challenge and riposte merupakan sebuah kompetisi untuk menguji peringkat sosial seseorang. Kompetisi ini terdiri dari sebuah tantangan yang dapat merusak kehormatan seseorang, dan sebuah respon untuk menjawab tantangan tersebut, bahkan dapat digunakan untuk memberikan tantangan kepada penantang. Kitab-kitab Injil banyak mencatat tentang challenge yang dilakukan oleh orang Farisi dan ahli-
} 
Shame terbagi dalam dua pengertian yakni yang bermakna positif dan yang bermakna negatif. Shame yang positif berarti sensitivitas terhadap reputasinya sendiri dan opini dari orang lain. Bruce Malina mengatakan, "a sense of shame makes the contest of living possible, dignified, and human, since it implies acceptance of and respect for the rule of human interaction". ${ }^{12}$ Sebaliknya, seseorang yang kehilangan rasa malu yang positif, akan menjadi pribadi yang memalukan, yang memiliki reputasi yang tidak terhormat karena berada di luar batas adab yang dapat diterima masyarakat, ${ }^{13}$ yang berprilaku dengan cara-cara yang bertentangan dengan nilai-nilai masyarakat atau kelompok. $^{14}$

Pada saat honor dilihat sebagai hak prerogatif yang dimiliki oleh seseorang secara eksklusif, maka honor selalu merujuk pada laki-laki, dan shame merujuk pada perempuan. ${ }^{15}$ Laki-laki akan berkompetisi untuk mendapatkan kehormatan di arena publik, sedangkan perempuan diharapkan dapat mempertahankan kehormatan keluarga melalui kekudusannya. ${ }^{16}$ Kehormatan laki-laki (male honor) dilambangkan dalam testis dan perilaku laki-laki seperti kejantanan, keberanian, berotoritas, mempertahankan kehormatan keluarga, peduli terhadap prestise dan keunggulan sosial. ${ }^{17}$ Sedangkan rasa malu perempuan (female shame) dilambangkan dalam keperawanan dan perilaku perempuan yang memiliki sensitivitas terhadap ketelanjangan, memiliki sifat pemalu, takut-takut, dapat menahan diri, dan menjaga eksklusivitas seksual. ${ }^{18}$

Kondisi ini memperlihatkan laki-laki dan perempuan memiliki arena yang berbeda dalam perolehan kehormatan. David A. deSilva menyatakan, "Man occupy the public spaces, while women are generally directed toward the private spaces of home and hearth". ${ }^{19}$ Dunia laki-laki adalah dunia publik, sedangkan dunia perempuan adalah dunia privat. Menjadi laki-laki berarti berurusan dengan hal-hal di luar rumah tangga yaitu di ruang publik, begitupun perempuan, harus berurusan dengan hal-hal di dalam rumah

ahli Taurat terhadap Yesus (Malina and Rohrbaugh, Social Science Commentary on the Synoptic Gospels, 334).

${ }^{12}$ Malina and Neyrey, "Honor and Shame in Luke-Acts: Pivotal Values of the Mediterranean World", 51.

13 Ibid., 51.

14 David A DeSilva, Honor, Patronage, Kinship \& Purity: Unlocking New Testament Culture (Downers Grove: IVP Academic, 2000), 25.

${ }^{15}$ Malina and Neyrey, "Honor and Shame in Luke-Acts: Pivotal Values of the Mediterranean World", 51.

${ }^{16}$ Neyrey, Honor and Shame in the Gospel of Matthew, 32.

${ }^{17}$ Malina and Neyrey, "Honor and Shame in Luke-Acts: Pivotal Values of the Mediterranean World", 51.

18 Ibid.

${ }^{19}$ DeSilva, Honor, Patronage, Kinship \& Purity: Unlocking New Testament Culture, 33. 
tangga, yaitu ruang privat. $^{20}$ Itulah sebabnya, perempuan harus berhati-hati ketika meninggalkan rumah, harus menghindari percakapan dengan laki-laki lain. Tempat-tempat yang dikunjungi juga adalah tempat-tempat yang memang banyak dikunjungi oleh perempuan seperti sumur dan pasar, yang dapat dikatakan sebagai ekstensi dari ruang privat. $^{21}$

Alasan yang menempatkan perempuan dalam ruang privat didasarkan pada konsep bahwa perempuan bukanlah entitas yang berdiri sendiri, tetapi entitasnya tertanam di dalam identitas dan kehormatan dari laki-laki, seperti ayahnya atau suaminya. ${ }^{22}$ Seorang perempuan yang telah menikah senantiasa di bawah otoritas suaminya, ia dikontrol oleh kehendak suaminya, ia harus taat pada suaminya dalam segala hal dan senantiasa melayani suaminya (seperti mencuci kaki suaminya). ${ }^{23}$ Perempuan dituntut untuk aktif dalam ruang privatnya dan pasif di ruang publik. ${ }^{24}$

\section{Melihat Peranan Perempuan di Yohanes 12:1-8 melalui Konsep Honor and Shame}

a. Peranan Marta

Ayat 1-2: ${ }^{1}$ Enam hari sebelum Paskah Yesus datang ke Betania, tempat tinggal Lazarus yang dibangkitkan Yesus dari antara orang mati. ${ }^{2}$ Di situ diadakan perjamuan untuk Dia dan Marta melayani, sedang salah seorang yang turut makan dengan Yesus adalah Lazarus.

Pencantuman waktu enam hari oleh Yohanes mengindikasikan maksud penulis untuk mengarahkan perhatian pembaca pada kenyataan bahwa kisah di Yohanes 12:1-8 ini merupakan sebuah introduksi dari sebuah kisah spektakuler yakni kisah kematian Yesus. ${ }^{25}$ Rujukan kepada waktu historis ini merupakan sebuah antisipasi terhadap proklamasi Yesus tentang datangnya "waktu bagi Anak Manusia untuk dimuliakan" (12:23), ${ }^{26}$ sebuah antisipasi terhadap kematian, penguburan, dan kebangkitan-Nya. Yohanes ingin memulai minggu sengsara Yesus melalui sebuah kisah perjamuan dan pengurapan.

\footnotetext{
${ }^{20}$ Neyrey, Honor and Shame in the Gospel of Matthew, 29.

${ }^{21}$ DeSilva, Honor, Patronage, Kinship \& Purity: Unlocking New Testament Culture, 33.

${ }^{22}$ Ibid., 34.

${ }^{23}$ Mary J Evans, Woman in the Bible: An Overview of All the Crucial Passages on Women's Roles (Downers Grove: Intervarsity Press, 1984), 34.

${ }^{24}$ Mary Evans mengatakan kalau perempuan diharapkan sedapat mungkin tidak berada di ruang publik, yang berarti tidak meninggalkan rumah. Evans mengutip pendapat Philo yang mengatakan, "women are best suited to the indoor life which never strays from the house" (Ibid., 34)

${ }^{25}$ Gerald L Borchert, John 12-21: An Exegetical and Theological Exposition of Holy Scripture (Nashville: Holman Reference, 2002), 34.

${ }^{26}$ Margaret Beirne, Women and Men in the Fourth Gospel (London: T\&T Clark, 2004), 142.
} 
Besar kemungkinan bahwa perjamuan yang dikhususkan untuk Yesus tersebut merupakan sebuah perayaan akan bangkitnya Lazarus, sekaligus menjadi pertanda akan dibasuhnya kaki para murid oleh Yesus dalam perjamuan terakhir. ${ }^{27}$ Pada dasarnya, tidak lazim bagi seorang perempuan untuk mengikuti perjamuan bersama laki-laki. Perempuan yang demikian akan dipertanyakan reputasinya. ${ }^{28}$ Para antropolog berpendapat bahwa perjamuan pada zaman dahulu disebut sebagai “perayaan”. Mereka mengatakan, ${ }^{29}$

Ceremonies are regular, predictable events in which roles and statuses in a community are affirmed or legitimated. In other words, the microcosm of the meal is parallel to the macrocosm of everyday social relation ... Since eating together implied sharing a common set of ideas and values, and frequently a common social position as well (Luke 13:26), it is important to ask: who eats with whom, who sits where, what does one eat, where does one eat, who does what, how is it prepared, what utensils are used, when does one eat, what talk is appropriate, when does one eat what course. Answering such questions tells us much about the social relations a meal affirms.

Pendapat yang memperlihatkan perjamuan sebagai dunia mikro dari relasi sosial dalam masyarakat ini, secara otomatis menempatkan Marta dan Maria (yang notabene adalah perempuan) bukan sebagai tamu undangan maupun tuan rumah yang akan duduk semeja dengan Yesus. Tentu saja perempuan dapat hadir di sebuah perjamuan, tapi tidak untuk duduk semeja dengan laki-laki, melainkan lebih banyak berperan sebagai pelayan. Hal ini jelas terlihat dari cara Yohanes menandai kehadiran dan tindakan Marta di perjamuan tersebut sebagai dihko, nei. ${ }^{30}$

Tentunya tindakan melayani yakni dengan menyediakan makanan di atas meja, merupakan sebuah tugas yang tidak "shameful" bagi perempuan, karena tugas "household" ini memang merupakan ruang privat bagi seorang perempuan. Apalagi jika ia melakukan dengan cakap, maka hal ini akan mendatangkan pujian dan "honor" bagi tuan rumah yang mengadakan perjamuan tersebut. ${ }^{31}$ Ini berarti, seorang perempuan yang melayani para

${ }^{27}$ Craig S Keener, The Gospel of John: A Commentary, Volume 2. (Peabody: Hendrickson, 2004), 862.

${ }^{28}$ Malina and Rohrbaugh, Social Science Commentary on the Synoptic Gospels, 128.

${ }^{29}$ Ibid., 381 .

${ }^{30}$ dihko,nei berasal dari kata dasar diakonew. Kata ini secara umum berarti "to wait at table," yang merujuk kepada penyediaan makanan. Dalam pemahaman orang Yunani, melayani merupakan sebuah peran yang tidak terlalu dihargai. Karena itu, seorang laki-laki diharapkan untuk memerintah dan bukan melayani. Gerhard Kittel, Theological Dictionary of the New Testament, ed. Gerhard Kittel and Gerhard Friedrich, IV. (Grand Rapids: Eerdmans, 1965), 82.

31 Laki-laki diharapkan dapat berjuang untuk mendapatkan kehormatan di arena publik, maka perempuan diharapkan dapat mempertahankan kehormatan keluarga. Neyrey mengatakan, "females are by extension 'defensive' on behalf of the household, its stores as well as its reputation." Neyrey, Honor and Shame in the Gospel of Matthew, 32. 
tamu undangan dengan baik di sebuah perjamuan, akan dapat mempertahankan kehormatan keluarga dari tuan rumah tersebut. Dalam hal ini, dapat dikatakan bahwa Marta telah melayani dengan baik, karena tidak ada komentar yang negatif mengenai pelayanan yang telah ia berikan dan ini berarti bahwa kehormatan keluarganya dapat dipertahankan. Apalagi melihat relasi kasih yang ada di antara keluarga ini (Marta, Maria dan Lazarus) dengan Yesus (11:5), maka pelayanan yang Marta berikan juga dapat dipastikan berasal dari kasih dan penghormatannya kepada Yesus, yang disebutnya sebagai Guru, Tuhan, Mesias dan Anak Allah (11:27-28). Bagi orang Yahudi, melayani dapat memiliki makna yang lebih mendalam karena di dalamnya mengandung relasi antara pelayan dengan tuannya. Apalagi jika ia melayani seorang tuan besar yang termashyur, maka melayani bukan sebuah tugas yang tidak layak untuk dilakukan. Kata ini juga dapat memiliki konsep yang kuat tentang pelayanan yang didasarkan oleh kasih. Hal inilah yang membuat pelayanan Marta menjadi sebuah pelayanan yang dipandang sangat layak dan terhormat, serta patut untuk diteladani. ${ }^{32}$ Tidak mengherankan jika beberapa ahli memahami frasa "Ma, rqa dihko, nei" sebagai makna simbolik, yakni bahwa Marta menjadi sebuah paradigma dari konsep Yohanes tentang "servanthood.",33

\section{b. Peranan Maria}

Ayat 3: Maka Maria mengambil setengah kati minyak narwastu murni yang mahal harganya, lalu meminyaki kaki Yesus dan menyekanya dengan rambutnya; dan bau minyak semerbak di seluruh rumah itu.

Apabila pelayanan yang Marta berikan dipandang layak dan terhormat dalam pandangan masyarakat, maka tindakan seorang perempuan yang mengurapi kaki Yesus di perjamuan ini menimbulkan reaksi dan komentar dari para undangan yang ada. Matius dan Markus mencatat bahwa rekasi tersebut adalah reaksi kegusaran, yakni rasa marah dan rasa tidak senang dengan pengurapan yang dilakukan oleh perempuan ini (Mat. 26:8; Mrk. 14:4). Lukas memperlihatkan reaksi cemooh dari tuan rumah terhadap Yesus yang telah membiarkan dirinya dijamah oleh seorang perempuan berdosa (Luk. 7:39). Meskipun kisah di Injil Matius, Markus, Lukas, dan Yohanes tentang perempuan yang mengurapi Yesus dianggap sebagai beberapa peristiwa yang berbeda, tetapi tindakan mengurapi Yesus oleh seorang perempuan di sebuah perjamuan tetap menimbulkan reaksi dari publik. Adanya

\footnotetext{
${ }^{32}$ Kittel, Theological Dictionary of the New Testament, 83.

33 Robert Gordon Maccini, Her Testimony Is True: Women As Witnesses According to John (Sheffield: Sheffield Academic Press, 1996), 176-177.
} 
reaksi yang timbul terhadap tindakan perempuan yang mengurapi Yesus-Yohanes dengan jelas menyebut nama perempuan ini adalah Maria-mengindikasikan bahwa apa yang Maria lakukan bukanlah sesuatu yang lazim dan dianggap telah melewati batas-batas sosial yang ada. Tubuh manusia merupakan simbol dari masyarakat yang memiliki struktur yang kompleks dan batasan-batasannya. ${ }^{34}$ Batasan bagi tubuh adalah kulit dan hal yang mereplikasi batasan tersebut (seperti berpakaian). ${ }^{35}$ Tubuh yang adalah mikrokosmos dari tubuh sosial juga menunjukkan adanya hierarki yakni bagian tubuh yang lebih tinggi letaknya dipandang lebih terhormat daripada bagian tubuh yang lebih rendah. ${ }^{36}$ Dalam hal ini kepala, wajah, dan mata adalah lokus kehormatan seseorang. ${ }^{37}$ Kepala seseorang dihargai ketika dimahkotai atau diurapi, serta tidak dilecehkan (seperti dipukul). Pelayan dan abdi dalem menghormati raja dengan menghindari menatap wajah raja. ${ }^{38}$ Selain itu bagian lain yang dihormati adalah lengan dan tangan kanan. Organ kelamin laki-laki yang merupakan simbol kekuatan dan fertilitas seorang laki-laki juga merupakan bagian yang sangat dihormati. Sedangkan bagian yang tidak terhormat adalah kaki. ${ }^{39}$ Apabila bagian yang tidak terhormat ini diurapi, dicium, dan menjadi tempat bersujud, maka orang tersebut dianggap sebagai orang yang terhormat dalam masyarakat. ${ }^{40}$

Selain bagian-bagian tubuh, postur tubuh seseorang juga dapat mengekspresikan penghormatan terhadap orang lain. Postur membungkuk dan bersujud, secara jelas memperlihatkan penghormatan kepada seseorang yang olehnya ia membungkukkan diri. Begitu pula postur pelayan yang berdiri dan menunggu sementara tuannya duduk, merupakan sebuah postur penghargaan. ${ }^{41}$ Penghormatan terhadap seseorang dengan jelas diperlihatkan melalui postur tubuh dan tindakan yang dilakukannya. ${ }^{42}$

Secara khusus bagi perempuan, kekudusannya ditanamkan dalam kehormatan lakilaki, karena itu laki-laki ikut bertanggungjawab untuk menjaga keeksklusifan seksualitas

${ }^{34}$ Philip Francis Esler, Community and Gospel in Luke-Acts: The Social and Political Motivations of Lucan Theology (Cambridge: Cambridge University Press, 1989), 73.

${ }^{35}$ Malina and Neyrey, "Honor and Shame in Luke-Acts: Pivotal Values of the Mediterranean World", 283.

${ }^{36}$ Ibid., 284.

37 Jerome H. Neyrey, "Despising the Shame of the Cross," in The Gospel of John in Cultural and Rhetorical Perspective (Grand Rapids: Eerdmans, 2009), 416.

38 Ibid., 416.

${ }^{39}$ Neyrey, Honor and Shame in the Gospel of Matthew, 24.

${ }^{40}$ Ibid.

${ }^{41}$ Neyrey, "Despising the Shame of the Cross", 417.

${ }^{42}$ Bruce J Malina, The New Testament World: Insights from Cultural Anthropology (Louisville: Westminster John Knox, 1993), 41. 
seorang perempuan dalam keluarganya. ${ }^{43}$ Perempuan harus menghindari kontak dengan orang lain yang dapat membuatnya menjadi tidak terhormat atau memalukan. ${ }^{44} \mathrm{Hal}$ ini hanya akan berhasil jika didukung oleh otoritas dan kontrol laki-laki.

Dalam melindungi tubuhnya dari kontak dengan orang lain, perempuan harus berhati-hati untuk keluar dari rumahnya atau berada di ruang publik. Alangkah baiknya jika tetap berada di ruang privat yakni dengan tidak keluar dari rumah ayahnya. ${ }^{45}$ Walaupun ia keluar ke ruang publik, maka perlu ada ayah, saudara laki-laki atau suami yang berada di sampingnya. Plutarch sebagaimana dikutip oleh deSilva mengatakan, " $A$ good woman ... should be seen most when she is with her husband, and stay at home and be hidden when he is away". 46

Selain itu, cara perempuan berpakaian di ruang publik juga akan menghindarkan dirinya dari label memalukan dan tercemar. Perempuan, secara khusus perempuan Yahudi, harus melindungi rambutnya dari konsumsi publik, dengan cara menudunginya. ${ }^{47}$ Beberapa rabi menganggap bahwa pembacaan Shema di depan perempuan yang tidak berkerudung adalah tindakan yang melanggar hukum. ${ }^{48}$ Praktik menudungi kepala oleh perempuan, memperlihatkan posisi perempuan yang tunduk di bawah otoritas laki-laki (suaminya atau ayahnya). ${ }^{49}$ Menudungi kepala merupakan simbol bahwa seorang perempuan mengakui suaminya sebagai kepalanya dan berada di bawah otoritas suaminya. Karena itu, seorang perempuan tidak dapat sembarangan memperlihatkan kepalanya (yakni rambutnya) yang merupakan otoritas suaminya atau ayahnya, untuk dikonsumsi oleh publik. Rambut yang dilindungi dengan baik menandakan martabat yang baik pula, sedangkan rambut yang tidak dilindungi atau rusak (seperti digunduli) akan merendahkan martabat seseorang. ${ }^{50}$

Tidak mengherankan, jika tindakan Maria yang mengurapi kaki Yesus dengan minyak narwastu dan membasuhnya dengan rambutnya, akan mendapatkan cemooh. Alasannya jelas, rambut seorang perempuan yang harus dilindungi dengan ditudungi,

${ }^{43}$ Malina and Neyrey, "Honor and Shame in Luke-Acts: Pivotal Values of the Mediterranean World", 44.

${ }^{44}$ Ibid.

${ }^{45}$ DeSilva, Honor, Patronage, Kinship \& Purity: Unlocking New Testament Culture, 184.

${ }^{46}$ Ibid.

${ }^{47}$ Keharusan bagi perempuan Yahudi ini mungkin disebabkan karena adanya kebiasaan berpakaian dalam ibadah orang Yahudi di sinagoge (Stephen B Clark, Man and Woman in Christ: An Examination of the Roles of Men and Women in Light of Scripture and the Social Sciences (Ann Arbor: Servant Books, 1980).

${ }^{48}$ Ibid., 168.

${ }^{49}$ Ibid., 170-171.

${ }^{50}$ Craig R Koester, Symbolism in the Fourth Gospel: Meaning, Mystery, Community, 2nd ed. (Minneapolis: Augsburg Books, 2003), 129. 
ternyata dibiarkan terbuka oleh Maria, dan digunakan untuk membasuh kaki seorang lakilaki. Selain itu, dalam aksi mengurapi ini, Maria telah menjamah seorang laki-laki yang bukan keluarganya, dan dengan demikian, ia telah keluar dari ruang privatnya.

Namun uniknya, Yohanes tidak secara eksplisit memperlihatkan cemooh dan penghinaan dari para tamu terhadap Maria, seperti yang secara eksplisit diperlihatkan oleh Lukas ketika ada perempuan yang mengurapi kaki Yesus dan menyekanya dengan rambutnya. Beberapa dugaan yang dapat dikemukakan sehubungan dengan tidak dicatatnya reaksi penghinaan terhadap Maria atas tindakannya oleh Yohanes, antara lain; Pertama, Maria bukan “orang luar” bagi Yesus dan murid-murid-Nya. Yesus dan keluarga Maria memiliki hubungan yang dekat, terlihat bagaimana Ia singgah di rumah dari keluarga ini (Luk. 10:38), dan bagaimana Ia mengasihi mereka sekeluarga (11:5).

Bagi Maria sekeluarga, Yesus bukanlah outsider, begitupun bagi Yesus dan muridmurid-Nya (secara khusus bagi Yohanes), Maria sekeluarga bukanlah outsider. Sebuah hubungan kinship atau kekerabatan dengan Yesus ini membuat Yesus termasuk dalam ruang privat Maria, yang dapat dibasuh kakinya oleh Maria, seperti halnya seorang perempuan membasuh kaki ayahnya, atau suaminya, atau tuannya. ${ }^{51}$ Ada yang berpendapat bahwa postur tubuh Maria yang memperlihatkan sebuah tindakan penyembahan yang privat dan intim, dimungkinkan karena Yohanes tidak memberikan impresi mengenai sebuah peristiwa yang bersifat publik, ${ }^{52}$ dengan anggapan bahwa yang hadir hanya Yesus dan murid-murid-Nya. namun dugaan yang pertama tidak terlalu lazim diterima mengingat tidak adanya bukti yang eksplisit bahwa yang hadir di perjamuan tersebut hanya Yesus dan murid-murid-Nya.

Kedua, pengurapan yang dilakukan oleh Maria dilihat sebagai sebuah penanggalan diri yang total untuk memberikan penghormatan yang total. Dalam budaya masyarakat pada saat itu, tindakan membasuh kaki merupakan hal yang biasa dilakukan oleh diri sendiri maupun oleh seorang pelayan. ${ }^{53}$ Tuan rumah akan menyediakan air, rempahrempah atau minyak bagi tamunya agar tamunya dapat membasuh kakinya sendiri, atau dibasuh oleh seorang pelayan ${ }^{54}$. Para rabi mengizinkan anak-anak untuk membasuh kaki orang tuanya, tetapi tidak mengharapkan mereka untuk melakukan hal tersebut. Hal ini memperlihatkan bahwa selain diri sendiri, hanya pelayan yang dapat diharapkan untuk

\footnotetext{
${ }^{51}$ Ibid., 128.

52 J. F Coakley, "The Anointing at Bethany and the Priority of John," Journal of Biblical Literature 107, no. 2 (1988).

${ }_{53}$ Koester, Symbolism in the Fourth Gospel: Meaning, Mystery, Community, 127-128.

54 John Christopher Thomas, Footwashing in John 13 and the Johannine Community (New York: Continuum International, 1993), 56.
} 
membasuh dan mengurapi kaki orang lain. ${ }^{55}$ Seseorang yang dengan sukarela membasuh kaki yang lainnya memperlihatkan bahwa ia berkenan untuk merendahkan dirinya seperti seorang pelayan bagi orang tersebut, dan hal itu dilakukan sebagai sebuah tindakan kasih dan penghormatan terhadap orang tersebut. ${ }^{56}$ Hal inilah yang diperlihatkan oleh Maria melalui pengurapannya kepada Yesus.

Ada tiga hal yang memperlihatkan penanggalan diri/ perendahan diri yang total dari Maria melalui kerelaannya untuk mengurapi kaki Yesus: (1) ia mempersembahkan minyak narwastu sebanyak 324 grams (yang dianggap sebagai sebuah pemborosan), dengan harga yang sangat mahal (sebesar gaji pekerja harian selama satu tahun). ${ }^{57}$ Mahalnya minyak ini-yang tidak banyak orang dapat memilikinya-menjadikan minyak ini sebagai sebuah pusaka bagi seorang perempuan, ${ }^{58}$ yang secara umum akan digunakan pada hari pernikahannya. ${ }^{59}$ Hal ini merepresentasikan seluruh harta Maria dipersembahkan di kaki Yesus. John Thomas menyatakan bahwa penggunaan minyak narwastu oleh Maria sebagai ganti air juga memperlihatkan motivasi dari tindakan Maria adalah kasih. ${ }^{60}$ (2) ia memperlihatkan postur tubuh seorang hamba, yang bersujud di kaki tuannya. Melayaninya dan membasuh kaki tuannya. (3) ia memperlihatkan penyembahan yang total kepada Yesus. Maria bukan sekadar memperlihatkan relasi seorang hamba dengan tuannya, tetapi relasi seorang penyembah yang mengasihi Tuhannya. Maria menggunakan rambutnya, martabatnya, lambang otoritas laki-laki terhadap dirinya, untuk membasuh kaki Yesus. Hal ini dengan jelas menunjukkan bagaimana Maria dengan sepenuh hati membiarkan Kristus berotoritas sepenuhnya atas dirinya. Rambutnya yang menempati posisi yang tinggi dalam hierarki tubuhnya, ditundukkan di bagian paling rendah dari tubuh seseorang, yakni pada kaki Yesus. Bahkan seorang pelayan yang hanya menyentuh kaki tuannya saja sudah dianggap rendah, ${ }^{61}$ apalagi Maria yang membasuh kaki tersebut dengan rambutnya. Semua ini dilakukan bukan karena paksaan sebagai seorang budak atau tawanan, atau tuntutan sosial pada seorang anak atau istri, melainkan dengan sukarela karena kasih. ${ }^{62}$ Inilah penyembahan yang sesungguhnya.

Postur tubuh dan tindakan pengurapan yang Maria lakukan ini, "dibaca" oleh Yohanes sebagai sebuah sikap dari seorang hamba dan penyembah yang penuh kasih

\footnotetext{
${ }^{55}$ Koester, Symbolism in the Fourth Gospel: Meaning, Mystery, Community, 128.

56 Thomas, Footwashing in John 13 and the Johannine Community, 56.

${ }^{57}$ Borchert, John 12-21: An Exegetical and Theological Exposition of Holy Scripture, 32.

${ }^{58}$ Neyrey, "Despising the Shame of the Cross", 864.

${ }^{59}$ Borchert, John 12-21: An Exegetical and Theological Exposition of Holy Scripture, 38.

${ }^{60}$ Thomas, Footwashing in John 13 and the Johannine Community, 57.

${ }^{61}$ Keener, The Gospel of John: A Commentary, 863.

${ }^{62}$ Thomas, Footwashing in John 13 and the Johannine Community, 57.
} 
melayani dan menyembah Tuannya, daripada sikap seorang perempuan pendosa yang sedang melecehkan dirinya di hadapan publik. Sikap Maria yang "dibaca" oleh Yohanes inilah yang kemudian dituangkannya dalam bentuk narasi untuk dibaca juga oleh komunitas asuhan Yohanes. Itulah alasan mengapa Yohanes tidak mengungkapkan adanya kegusaran dan celaan dari tamu yang ada.

Ketiga, Yohanes hendak menonjolkan peranan Maria yang berfokus pada proklamasi dari kematian dan penguburan Yesus, ${ }^{63}$ daripada "pelanggaran" batasan sosial dalam pandangan masyarakat pada saat itu. Hal ini juga terlihat dari cara Yohanes membandingkan Maria dengan Yudas, yang dengan jelas menonjolkan peran positif dari Maria. Dengan demikian, Yohanes memperlihatkan honor-nya Maria, daripada pandangan masyarakat yang menganggapnya shameful.

Dugaan bahwa Yohanes hendak menonjolkan peranan Maria sehingga ia tidak mencantumkan secara eksplisit respon negatif dari para tamu, dapat terlihat dari ayat-ayat selanjutnya dari narasi ini. Ayat 4-8: ${ }^{4}$ Tetapi Yudas Iskariot, seorang dari murid-murid Yesus, yang akan segera menyerahkan Dia, berkata; ${ }^{5}$ Mengapa minyak narwastu ini tidak dijual tiga ratus dinar dan uangnya diberikan kepada orang-orang miskin?“ ${ }^{6} \mathrm{Hal}$ itu dikatakannya bukan karena ia memperhatikan orang-orang miskin, melainkan karena ia adalah seorang pencuri; ia sering mengambil uang yang disimpannya dalam kas yang dipegangnya. ${ }^{7}$ Maka kata Yesus: "Biarkanlah dia melakukan hal ini mengingat hari penguburanKu." ${ }^{8}$ Karena orang-orang miskin selalu ada pada kamu tetapi Aku tidak akan selalu ada pada kamu."

Ayat-ayat tersebut memperlihatkan cara Yohanes menonjolkan peranan Maria, yakni mengontraskan Maria dengan Yudas. menggunakan penjelasan yang cukup panjang untuk menggambarkan Yudas sebagai kontras dengan Maria. Peristiwa pengurapan oleh seorang perempuan terhadap Yesus dalam ketiga injil yang lain, sama sekali tidak mencantumkan nama Yudas, sama halnya dengan tidak dicantumkannya nama perempuan tersebut. Namun Yohanes dengan jelas mencantumkan nama Maria dan Yudas Iskariot sebagai sebuah kontras di antara keduanya.

Argumentasi Yudas tentang memberi kepada orang miskin sebenarnya bukan hal yang mengherankan pada masa itu. Dalam masyarakat yang dikatakan "limited-good society", minyak yang banyak dan sangat mahal ini, yang hanya dicurahkan pada kaki tamu di sebuah perjamuan, dianggap sebagai pemanjaan diri dan pemborosan, sehingga

${ }^{63}$ Borchert, John 12-21: An Exegetical and Theological Exposition of Holy Scripture, 35. 
merupakan sebuah bentuk pencurian sosial. ${ }^{64}$ Cara untuk menebus hal tersebut adalah memberi kepada orang miskin sebagai sebuah bentuk restitusi sosial. ${ }^{65}$ Namun argumen yang terdengar baik dari Yudas ini segera dipatahkan oleh Yohanes dengan sangat tegas ketika ia menyatakan bahwa Yudas adalah seorang pencuri yang tidak peduli dengan nasib miskin.

Selain itu, pernyataan Yesus di ayat ketujuh, dengan jelas memperlihatkan pengurapan mewah yang Maria lakukan bukanlah sebuah kejahatan sosial, melainkan sebuah tindakan yang memiliki makna spiritual yang sangat penting. ${ }^{66}$ Kejahatan sosial tidak dapat dihapuskan sepenuhnya hanya dengan restitusi sosial yakni memberi kepada orang miskin. Kejahatan tetaplah kejahatan, dosa tetaplah dosa, yang hanya akan mendapatkan pengampunan melalui penebusan dari Kristus. Pada saat para tamu digiring opininya oleh Yudas untuk melakukan restitusi sosial kepada orang miskin, maka Yesus sedang membicarakan tentang pengampunan dan penebusan yang seutuhnya yang akan dibayar oleh-Nya sebentar lagi melalui kematian-Nya. Pengurapan yang Maria lakukan bagi Yesus, yang hanya berlangsung sekali, merupakan proklamasi tentang restitusi yang sepenuhnya, yang akan dibayar bukan oleh manusia yang berdosa, melainkan oleh Yesus melalui kematian-Nya.

Identifikasi Yohanes tentang pribadi Yudas di ayat keenam, dan pernyataan Yesus di ayat ketujuh dan delapan, telah menempatkan Yudas sebagai murid yang munafik, yang hendak memberikan kesan sebagai orang yang terhormat di mata publik, tetapi memiliki hati yang busuk di dalamnya. Sangat kontras dengan profil Maria yang ditampilkan di narasi Yohanes ini. Maria, seorang perempuan yang menyerahkan dirinya kepada Yesus dengan memberikan totalitas penyembahan dari seluruh dirinya dan hartanya, berbanding terbalik dengan Yudas, yang menyerahkan Yesus demi mendapatkan tiga puluh keping perak bagi dirinya. Sebuah kontras yang menempatkan Yudas sebagai murid yang sangat menyedihkan. Tidak mengherankan jika Yohanes dalam Injilnya, tanpa basa basi lagi, menyebut Yudas sebagai Iblis (6:70), kerasukan setan (13:27), yang telah ditentukan untuk binasa (17:12), pengkhianat (18:5), dan pencuri yang tidak peduli dengan orang-orang miskin $(12: 6){ }^{67}$

Pengontrasan Maria dan Yudas ini telah memberikan sebuah posisi yang terhormat kepada Maria dan posisi yang tidak terhormat bagi Yudas. Posisi yang terhormat dari

\footnotetext{
${ }^{64}$ Malina and Rohrbaugh, Social Science Commentary on the Synoptic Gospels, 128.

${ }^{65}$ Ibid.

66 Ibid., 128.

${ }^{67}$ Borchert, John 12-21: An Exegetical and Theological Exposition of Holy Scripture, 36.
} 
Maria ini dengan jelas diperlihatkan oleh Yohanes melalui perkataan Yesus di ayat ketujuh yang memperlihatkan pentingnya peranan pengurapan yang Maria lakukan.

Komentar Yesus kepada Yudas diawali dengan sebuah kalimat perintah: Let her alone! Kata "let" (a;fej) yang menggunakan bentuk imperatif aorist aktif ${ }^{68}$ ini menjadikan ucapan Yesus menjadi sebuah teguran yang tegas kepada Yudas. Kata afej yang disertai dengan kata auvth,n memperlihatkan bahwa Yesus memerintahkan Yudas dengan tegas untuk melakukan single simple act yakni membiarkan Maria melakukan apa yang sedang dilakukannya.

Teguran Yesus yang keras kepada Yudas telah melindungi Maria dari segala bentuk perendahan dari publik karena anggapan bahwa Maria telah melakukan kejahatan sosial. Teguran ini juga merupakan sebuah pembelaan terhadap Maria, yang secara tidak langsung merupakan pembenaran terhadap tindakan Maria, bahwa Maria tidak melakukan sesuatu yang memalukan, melainkan sesuatu yang sangat penting dan terhormat. Penerimaan Yesus atas penghormatan yang Maria berikan, telah menempatkan Maria sebagai perempuan yang tidak memalukan, melainkan terhormat. ${ }^{69}$

Perintah Yesus kepada Yudas untuk let Mary alone dalam melakukan hal yang penting ini sekalipun harus dilakukan di ranah publik, tidak berarti bahwa Yesus membuang honor code dalam masyarakat, tetapi Ia mendefinisikan ulang apa yang merupakan honor dalam pandangan-Nya. ${ }^{70}$ Pada akhirnya, di pasal 13, Yesus sendiri melakukan tindakan pembasuhan kaki kepada murid-murid-Nya, yakni sebuah tindakan yang dianggap tidak terhormat tetapi diberi makna oleh Yesus menjadi sebuah tindakan terhormat yang harus diteladani oleh pengikut-Nya. Paralelnya struktur di pasal 12 dan 13 ini memperlihatkan sebuah pengulangan yang bertujuan untuk memberikan klimaks kepada peristiwa kematian Yesus secara lebih eksplisit. ${ }^{71}$

68 Kata a; fej hanya muncul tiga kali di Injil Yohanes, yakni di 12:7 ini; di 11:44 (Ketika Yesus membangkitkan Lazarus dan memerintahkan orang-orang untuk membuka kain kafannya Lazarus, lalu membiarkan Lazarus pergi); dan di 18:8 (ketika Yesus ditangkap di Taman Getsemani, Ia memerintahkan para pasukan tersebut untuk menangkap-Nya saja dan membiarkan murid-murid-Nya pergi). Melalui contoh dari penggunaan a; fej di 11:44 dan 18:8, dapat dilihat bahwa kata a; fej ini merupakan sebuah kalimat perintah yang tegas untuk benar-benar membiarkan pergi objek yang dimaksud.

${ }^{69}$ Kitab-kitab Injil memperlihatkan pola di mana perkataan dan tindakan dari Yesus telah membuat seseorang yang dianggap masyarakat tidak terhormat menjadi terhormat. Contohnya, the social worldIa membiarkan diri-Nya dijamah oleh perempuan yang tercemar karena sakit pendarahan, dan berkata kepadanya; Hai anak-Ku, imanmu telah menyelamatkan engkau, pergilah dengan selamat" (Luk. 8:48). Jerome H. Neyrey, "The Symbolic Universe of Luke-Acts: "They Turn the World Upside Down"," in Malina and Rohrbaugh, The Social World of Luke-Acts: Models for Interpretation..

${ }^{70}$ Neyrey menjelaskan bagaimana Yesus mendefinisikan ulang makna honor melalui ucapan bahagia di Matius 5:3-12. Neyrey, Honor and Shame in the Gospel of Matthew, 164.

${ }^{71}$ Keener, The Gospel of John: A Commentary, 859. 
Rujukan klimaks kepada peristiwa kematian Yesus menjadi alasan pentingnya peranan Maria pada kisah ini. Hal ini diperlihatkan melalui kalimat "in order that she may keep it for the day of my burial". Frasa "keep it" (thrh, sh auvto, ) di sini tidaklah merujuk kepada tindakan Maria untuk menyimpan minyak narwastu tersebut untuk digunakan pada suatu peristiwa di masa depan, misalnya untuk penguburan Yesus, tetapi lebih merujuk kepada proses penjelasan tentang tujuan dari tindakan pengurapan yang dilakukan Maria. $^{72}$

Pengurapan khusus yang Maria lakukan, dengan kerelaannya, dengan kasihnya, dengan penyembahannya, dengan gestur tubuhnya yang merendah, dengan rambutnya yang digunakan untuk menyeka kaki Yesus, dengan kuantitas dan kualitas dari minyak yang digunakan, serta dengan wangi semerbak yang memenuhi rumah tersebut, semuanya diarahkan dengan tujuan untuk menonjolkan pribadi Kristus sebagai yang layak ditinggikan dan dimuliakan melebihi segala sesuatu. ${ }^{73}$

Penonjolan pada pribadi Yesus dan karya keselamatan-Nya memang menjadi pusat dari Injil Yohanes. Narasi Yohanes yang dirajut sedemikian rupa, dipusatkan pada Yesus dan misi mesianik-Nya untuk dibawa kepada satu tujuan, yakni supaya orang-orang percaya bahwa Yesuslah Mesias, Anak Allah, dan supaya dengan iman seseorang memperoleh hidup dalam nama-Nya (20:31). Karena itu, semua image, action, dan person yang terdapat dalam tulisan Yohanes dipusatkan pada Yesus, dengan tujuan untuk memperlihatkan siapa Yesus sehingga orang-orang dapat mengenal-Nya dan mengimaniNya. $^{74}$ Semua orang yang berjumpa dengan Yesus memainkan peranan yang vital dalam narasi yang ada untuk membuat Yesus dikenal dan disembah.

Dengan demikian, peristiwa pengurapan Maria yang dicatat oleh Yohanes di Yohanes 12:1-8, bahkan yang telah diperkenalkan sebelumnya di Yohanes 11:2, bukanlah sebuah peristiwa yang tidak memilki arah tujuan. Tujuannya jelas diarahkan pada Kristus dan misi mesianik-Nya. Apalagi peristiwa ini dicatat mendahului peristiwa masuknya Yesus ke Yerusalem (12:12), dengan jelas menonjolkan maksud Yohanes untuk memperlihatkan bahwa Yesus masuk ke Yerusalem sebagai Raja yang telah mendapatkan pengurapan. $^{75}$

\footnotetext{
${ }^{72}$ Marianne Meye Thompson, John: A Commentary (Louisville: Westminster John Knox, 2015), 261.

${ }^{73}$ Beirne, Women and Men in the Fourth Gospel, 148.

${ }^{74}$ Koester, Symbolism in the Fourth Gospel: Meaning, Mystery, Community, 4.

75 George R Beasley-Murray, Word Biblical Commentary Vol. 36, John (Nashville: Thomas Nelson
} Inc, 1999), 208. 
Pada dasarnya, pengurapan pada kepala seseorang mengandung tema kingship di dalamnya, tetapi Yohanes memperlihatkan pengurapan pada kaki Yesus oleh Maria memiliki motif untuk menonjolkan Yesus sebagai Raja yang bukan berasal dari dunia ini (Yoh. 18:36), dan yang harus menderita di dunia ini demi menjalankan misi penyelamatanNya. Yesus adalah Raja atas segala raja, yang melayani dengan penuh kasih sampai mati. He is the servant King! Maria berhasil membawa tema pelayan dan raja di dalam tindakan pengurapan yang dilakukannya. ${ }^{76}$ Pengurapan oleh Maria yang diterima oleh Yesus bertujuan untuk mempersiapkan penobatan sekaligus penguburan-Nya. ${ }^{77}$ Craig Koester memperjelas hubungan antara pengurapan dan kematian serta kemuliaan Yesus sebagai Raja dengan mengatakan, "the regal amount of ointment cannot be understood apart from his death, and yet his death should also be understood in light of the anointing, for through his crucifixion Jesus reigned as king", 78

Tidak ada yang dapat memastikan apakah Maria memang melakukan pengurapan tersebut untuk mempersiapkan kematian Yesus, atau ia hanya ingin memerlihatkan pengabdian, penyembahan, dan cinta kasihnya kepada Yesus melalui pengurapan tersebut. Ada kemungkinan bahwa Maria memang tidak mengetahui bahwa pengurapan yang dilakukannya memiliki peranan yang demikian signifikan. Namun Yesuslah yang memberikan makna terhadap apa yang dilakukan olehnya. Bagi Yesus, pengurapan yang Maria lakukan merupakan sebuah simbol $^{79}$ yang mengantisipasi hari penguburan-Nya. ${ }^{80}$ Minyak narwastu yang tercurah di kaki Yesus merupakan sebuah respon proleptik $^{81}$ kepada pemberian diri Kristus melalui kematian-Nya. ${ }^{82}$

Pengurapan pada kepala Yesus oleh perempuan di Injil Matius dan Markus memperlihatkan sebuah tindakan profetik tentang Yesus sebagai Raja yang diurapi, maka pengurapan Maria pada kaki Yesus merupakan sebuah tindakan profetik yang mempersiapkan penguburan bagi Yesus. ${ }^{83}$ Melalui pengurapannya, Maria memperlihatkan

\footnotetext{
${ }^{76}$ Beirne, Women and Men in the Fourth Gospel, 153.

${ }^{77}$ Koester, Symbolism in the Fourth Gospel: Meaning, Mystery, Community, 130.

${ }^{78}$ Ibid., 130.

${ }^{79}$ Simbol adalah an image, an action, or a person that is understood to have transcendent significance (Ibid., 4).

${ }^{80}$ Beirne, Women and Men in the Fourth Gospel, 154.

${ }^{81}$ Proleptik atau prolepsis adalah the anticipation of possible objections in order to answer them in advance; the representation of something in the future as if it already existed or had occured. Dictionary.Com, "Definition of Proleptic," Www.Dictionary.Com, accessed October 22, 2019, https://www.dictionary.com/browse/proleptic.

${ }^{82}$ Koester, Symbolism in the Fourth Gospel: Meaning, Mystery, Community, 129.

83 Barbara E. Reid, "Mary of Bethany, a Model of Listening," accessed October 25, 2019, http://www.osservatoreromano.va/en/news/mary-bethany-model-listening.
} 
"a tacit act of witness" $" 84$ tentang kematian Yesus. Maria bersaksi dalam kesenyapan katakata, ia bersaksi dengan tindakannya. Maria bagaikan seorang nabi yang sedang menjalankan tugas untuk mengurapi dan bersaksi. Sebagaimana Robert Maccini mengutip dari J. Rena dengan mengatakan, “Jesus portrays her as a prophet anointing to and even participating in his burial". ${ }^{85}$

Dalam hal ini, pemberian makna dari Yesus atas tindakan Maria menjadikannya sebagai seorang pelayan dan penyembah yang mengemban tugas kenabian dengan "menubuatkan" kematian Yesus melalui perbuatannya. Peranan yang prestise ini diberikan langsung oleh Tuhan. Mengingat rabi dan nabi merupakan contoh dari label-label yang dianggap terhormat dan cenderung diperebutkan, ${ }^{86}$ maka tugas kenabian yang diemban oleh Maria telah menempatkan dirinya dalam posisi yang sangat penting dan terhormat.

\section{Kesimpulan}

Yohanes tidak secara eksplisit mengajarkan tentang peranan perempuan dalam Injilnya, tetapi ia memberikan gambaran jelas tentang para perempuan yang memiliki peran signifikan dalam melayani Tuhan. Marta dan Maria menjadi contoh bagaimana seharusnya melayani. Walaupun mereka melayani di bidang yang berbeda, tetapi mereka melakukan dengan penuh kasih dan penghormatan kepada Yesus. Marta memberikan yang terbaik bagi Yesus dengan menjamu Yesus dan para undangan lainnya sebaik mungkin. Di sisi lain, Maria dengan pelayanannya yang mengundang kontroversi, tetapi mendapat afirmasi dari Yesus.

Maria adalah pelayan yang dengan sukarela memberikan totalitas diri dan hartanya kepada Tuhan yang dikasihinya. Ia memberikan pelayanan yang "termahal" yang sanggup diberikannya kepada Tuhannya. Walaupun ia dapat dianggap melanggar batas-batas privat seorang perempuan, tetapi ia tetap melangkah ke luar ruang privatnya menuju ruang publik untuk menemukan Tuhannya di sana dan melayani-Nya.

Pelayanan Maria merupakan sebuah proleptik yang memiliki makna profetik di dalamnya yakni sebuah pemberitahuan awal tentang kematian dan penguburan-Nya. Maria menjalankan tugas kenabian dengan mengurapi dan bersaksi dalam kesenyapan. Peran ini

${ }^{84}$ Maccini, Her Testimony Is True: Women As Witnesses According to John, 178.

${ }^{85}$ Ibid.

${ }^{86}$ Jerome H Neyrey, "Despising the Shame of the Cross: Honor and Shame in the Johannine Passion Narrative," Semeia 68 (1994): 116. 
diberikan secara langsung oleh Yesus, yang berarti bahwa peranan profetik yang disandang oleh Maria ditetapkan oleh Yesus sendiri.

Pada akhirnya, tindakan pengurapan yang Maria lakukan, jika diparalelkan dengan pembasuhan kaki yang Yesus lakukan terhadap murid-murid-Nya, maka perintah Yesus bagi murid-murid-Nya untuk meneladani-Nya, mau tidak mau akan teringat kepada apa yang sebelumnya telah dilakukan oleh Maria kepada Yesus. Karena itu, tradisi pembasuhan kaki bagi komunitas umat percaya hingga saat ini, yang didasarkan pada apa yang telah diteladankan oleh Yesus menjelang kematian-Nya, akan juga mengingat tindakan pembasuhan yang dilakukan oleh seorang perempuan bernama Maria bagi Yesus.

Marta dan Maria adalah teladan bagi semua orang, baik laki-laki maupun perempuan, yang ingin melayani-Nya dengan segenap hati dan di bidangnya masingmasing sesuai dengan talenta dan panggilan yang telah diberikan oleh Tuhan. Peranan para perempuan yang signifikan dalam kisah ini, menjadi sebuah ingatan bagi gereja Tuhan untuk memberikan kesempatan bagi setiap perempuan agar dapat melayani-Nya. "Let her alone!" kiranya menjadi sebuah teguran yang terngiang-ngiang di "telinga" gereja-gereja yang sedang dan hendak mendiskreditkan perempuan yang sepenuh hati ingin melayaniNya dan terpanggil untuk melayani-Nya.

\section{Kepustakaan}

Beasley-Murray, George R. Word Biblical Commentary Vol. 36, John. Nashville: Thomas Nelson Inc, 1999.

Beirne, Margaret. Women and Men in the Fourth Gospel. London: T\&T Clark, 2004.

Borchert, Gerald L. John 12-21: An Exegetical and Theological Exposition of Holy Scripture. Nashville: Holman Reference, 2002.

Clark, Stephen B. Man and Woman in Christ: An Examination of the Roles of Men and Women in Light of Scripture and the Social Sciences. Ann Arbor: Servant Books, 1980.

Coakley, J. F. "The Anointing at Bethany and the Priority of John." Journal of Biblical Literature 107, no. 2 (1988).

DeSilva, David A. Honor, Patronage, Kinship \& Purity: Unlocking New Testament Culture. Downers Grove: IVP Academic, 2000.

Dictionary.Com. "Definition of Proleptic." Www.Dictionary.Com. Accessed October 22, 2019. https://www.dictionary.com/browse/proleptic.

Elliott, John H. What Is Social Scientific Criticism? Minneapolis: Fortress, 1993.

Esler, Philip Francis. Community and Gospel in Luke-Acts: The Social and Political Motivations of Lucan Theology. Cambridge: Cambridge University Press, 1989. 
Evans, Mary J. Woman in the Bible: An Overview of All the Crucial Passages on Women's Roles. Downers Grove: Intervarsity Press, 1984.

J, Neyrey S., and Jerome H. The Gospel of John in Cultural and Rhetorical Perspective. Grand Rapids: Eerdmans, 2009.

Keener, Craig S. The Gospel of John: A Commentary. Volume 2. Peabody: Hendrickson, 2004.

Kittel, Gerhard. Theological Dictionary of the New Testament. Edited by Gerhard Kittel and Gerhard Friedrich. IV. Grand Rapids: Eerdmans, 1965.

Koester, Craig R. Symbolism in the Fourth Gospel: Meaning, Mystery, Community. 2nd ed. Minneapolis: Augsburg Books, 2003.

Maccini, Robert Gordon. Her Testimony Is True: Women As Witnesses According to John. Sheffield: Sheffield Academic Press, 1996.

Malina, Bruce J. The New Testament World: Insights from Cultural Anthropology. Louisville: Westminster John Knox, 1993.

Malina, Bruce, and Richard L. Rohrbaugh. Social Science Commentary on the Synoptic Gospels. Minneapolis: Fortress, 1993.

—. The Social World of Luke-Acts: Models for Interpretation. Peabody: Hendrickson, 1991.

Neyrey, Jerome H. Honor and Shame in the Gospel of Matthew. Louisville: Westminster John Knox, 1998.

Reid, Barbara E. "Mary of Bethany, a Model of Listening." Accessed October 25, 2019. http://www.osservatoreromano.va/en/news/mary-bethany-model-listening.

Reid OP, Barbara E. Choosing The Better Part?: Women in the Gospel of Luke. Collegeville: Michael Glazier, 1996.

Schaberg, Jane. "Luke,” The Women's Bible Commentary. Edited by Carol A. Newsom and Sharon H. Ringe. Louisville: John Knox, 1992.

Thiessen, Karen Heidebrecht. "Jesus and Women in the Gospel of John." Direction 19, no. 2 (1990).

Thomas, John Christopher. Footwashing in John 13 and the Johannine Community. New York: Continuum International, 1993.

Thompson, Marianne Meye. John: A Commentary. Louisville: Westminster John Knox, 2015. 